\title{
Effect of rowing posture on body measurements and skin- sportswear interface pressure and implications on garment fit
}

\section{Abstract}

Sportswear should fit well each individual athlete while preserving its ergonomic and pressure comfort upon sport-specific movements. This study aims to quantify the effect of two rowing postures on selected body measurements and skin-sportswear interface pressure for competitive rowers age 18-35. The results based on average body measurements of a total number of 74 male and female rowers indicate a considerable influence of catch and finish posture on both body measurements and interface skinsportswear pressure, regardless the gender. Back length and across back width were most affected by posture, and increased especially from static to catch position by $12 \%$ $(6.1 \mathrm{~cm})$ and $16 \%(6.5 \mathrm{~cm})$ for male rowers, and respectively by $11 \%(4.9 \mathrm{~cm})$ and $13 \%$ $(4.7 \mathrm{~cm})$ for female rowers. In general, posture led to larger influence on pressure than on anthropometrics of maximum $55 \%$ versus $16 \%$ for male and up to $82 \%$ versus $13 \%$ for female rowers respectively. The maximum interface pressure (e.g. $10 \mathrm{mmHg}$ ) was rather low which suggest there was no pressure discomfort. Prototypes were developed and the fit of the garments was investigated in various postures. For the considered fabrics and design, an increase of the garment pattern to accommodate the catch maximum changes led to a poor fit of the prototype MR58-CP which was generally too large, especially in static posture. On the contrary, prototype MR58-FP, that considered some finish rowing posture-related body changes and design adjustments based on experience with the first prototype and input from the test person had the best fit.

Key words: rowers, anthropometry, rowing posture, skin-sportswear interface pressure, garment fit 


\section{Introduction}

Sportswear should ensure great freedom of movement and perfect fit. The current textile markets offer textile products in a number of sizes which are based on average population body measurements. For target groups with body proportions that deviate from the average different sizing charts are needed to ensure good fit of casual wear in general and sportswear in particular. Along with other sport disciplines, rowing is a sport that potentially leads to significant body changes upon large training volume. Many studies were conducted in the last two decades (1997-2017) that investigated the anthropometric characteristics of rowers from different countries including Belgium, Croatia, Poland, Spain, Australia, Malesia, Sri Lanka, Japan and linked that to sport performance among others. The size of the anthropometric surveys varied from small studies including 20 elite Malaysian rowers (Suleiman et al. 2016), 25 Internationally successful Croatian rowers (Mikulic, 2009), 46 subjects from Sri Lanka (Perera et al., 2015), 53 Croatian rowing champions (Mikulic, 2008), 54 Polish competitive rowers (Forjasz 2011), 78 subjects from Japan (Yoshiga et al. 2000) up to large studies of up to 115 Spanish rowers (PenichetTomas et al., 2016), 200-300 Belgian subjects (Bourgois et al, 2000; Bourgois et al, 2001; Claessens et al. 2005) and more than 500 Australian rowers (Schranz et al. 2010, Schranz et al., 2012). In all these cases, a large number of 1D anthropometric measurements were taken manually and only few (Schranz et al. 2010) also collected 2D and 3D predictors (i.e. body volume \& surface area) by 3D Body scanning technology. Several studies characterized and compared anthropometric characteristics of female and male rowers with those of the general population of similar age: i.e. Belgian school boys (Bourgois et al. 2000, Bourgois et al. 2001), (Claessens et al. 2005) and Polish non-athletes (Forjasz 2011). Moreover, anthropometry of finalists and non-finalists was compared (Bourgois et al. 2000), sweep rowers versus scullers (Bourgois et al. 2001), those using short versus long paddles (Forjasz 2011) and lightweight versus heavyweight rowers (Schranz et al. 2010). For instance, one study (Bourgois et al. 2000, Bourgois et al. 2001) stated that junior rowers are larger than Belgian school boys age 17.50 .7$)$ years: rowers are taller (+ $12 \mathrm{~cm})$, heavier $(+17.5 \mathrm{~kg})$, have longer legs $(+6.7 \mathrm{~cm})$ and sitting length $(+5.4 \mathrm{~cm})$ and have larger biceps $(+4.8 \mathrm{~cm})$ and thigh girth $(+2.8 \mathrm{~cm})$. As compared with the general population, Australian heavyweight rowers were found to be larger (i.e. especially height, mass, 3D dimensions) while the lightweight rowers were similar or smaller than adult 
population and their body dimensions were less variable than those of the general population (Schranz et al. 2010). Finalists seem to be significantly heavier and taller than non-finalists and they have greater length/ breadth (except bicristal diameter)/girth (Bourgois et al. 2000) while sweep rowers have significantly larger length dimensions versus scullers (Claessens et al. 2005). A recent study (De Raeve et al. 2018) investigated anthropometry of 74 male and female elite rowers by 3D body scanning, compared it with the average population, developed body size charts for male elite rowers and investigated the fit of the sport garments. Among others, they found significant differences between the heavyweight male rowers and Belgian males of the same age.

Body measurements are mostly taken in static posture, or A-pose (arms and legs slightly spread) in case of 3D body scanning. Posture is particularly important for development of comfortable sportswear with adequate fit that doesn't restrict sport movements. Although the influence of posture on anthropometrics is well known, only a limited number of studies recently investigated posture in relationship with garment fit and recommended adjustments of the patterns of protective garments (Wang et al. 2011), (Loercher, Morlock and Schenk 2018), (Loercher et al. 2018), fire-fighters (Coca et al. 2010), workwear (Bragança et al. 2016), (Braganca et al. 2017), (Loercher, Morlock and Schenk 2017), and sportwear (Choi and Hong 2015). Posture-dependent changes were mostly assessed manually and challenges, limitations and laborious post-processing were reported by studies (Chi and Kennon 2006), (Choi and Ashdown 2011) that used 3D Body scanning technology for dynamic postures. The influence of rowing-related posture upon respiratory muscle pressure and flow generating capacity was investigated (Griffiths and McConnell 2012) but body measurement changes were not reported and to the authors knowledge no study investigates sportwear for rowers with respect to fit and posture .

Elastic fabrics are commonly used in tight-fit clothing to provide desired shape and room for body movement. Ergonomic wear comfort of sportswear can be evaluated by measuring the wearing pressure and other related sensations by both subjective and objective methods. Many studies were conducted to investigate the influence of compression garments (CG) on athletic performance and recovery (Engel and Sperlich 2016) and various types of interface pressure sensors (i.e. pneumatic, fluid filled, etc.) were used. Air-filled instruments Kikuhime $\AA$ and Picopress ${ }^{\circledR}$ which were characterized as reliable easy to use instruments (Partsch and Mosti 2010), (Brophy-Williams et al. 2014), were previously used in in-vivo studies (Van den Kerckhove et al. 2007) to assess 
pressure garments used in treatments and prevention of scars after burn, to assess the durability of the compression garments after repeated use and laundry cycles (Maqsood et al. 2017), just to mention a few applications.

It can be concluded that there is a lack of studies dealing with body changes due to sport-specific posture and the link with garment patterning and development of well fitted sportswear is missing. Rowing is an endurance sport that consists in ample, repetitive movements that involves both upper and lower limbs. It is therefore hypothesized that body measurements and skin-sportswear interface pressure will considerably change depending on the rowing posture and regardless the gender. Although previous studies reported deviation of rowers anthropometry from average population, they did not link that to garment development and neither investigated rowing posture in particular. The aim of this study was twofold. Firstly, we quantified the effect of two rowing postures on selected body measurements and skin-clothing interface pressure for male and female competitive rowers age 18-35 years. Secondly, sportswear prototypes were developed based on male rowers anthropometry and body changes found during rowing posture and their fit was investigated. The rest of the paper is organized as follows. Section 2 describes the target group and methodology used to assess rowing posture-dependent variations of the considered variables. The results are presented in Section 3 and compared with other studies. Moreover this section also deals with validation of garment fit and describes the materials used and the prototypes developed (Section 3.5.1) as well as fit assessment methodology and results (Section 3.5.2). Finally, in Section 4 the conclusions are summarized.

\section{Materials and methods}

\subsection{Target groups}

Large number of training hours likely lead to large changes in body measurements and shape. Therefore the target group of this study consists of competitive male $(\mathrm{M})$ and female $(F)$ rowers of age 18-35 years, divided in two categories: (a) lightweight category $M$ $(F)$ of maximum $72.5(59) \mathrm{kg}$ and $(\mathrm{b})$ heavyweight category $M(F)$ of maximum $90(75) \mathrm{kg}$. All participants were healthy adults who practice at least 3 times per week including regular training sessions on a rowing ergometer. The subjects were mainly recruited during the Belgian Championship BC (Hazewinkel, Belgium, September 2017) and the 
International Rowing Regatta (Gent, Belgium, May 2018). Upon their arrival all subjects were informed about the purpose of the study and methodology and written informed consent from all participants was obtained prior to the start of testing sessions. Firstly the body mass and height of the subjects was registered by an anthropometer KERN MPB-P and the Body Mass Index (BMI, $\mathrm{kg} / \mathrm{m}^{2}$ ) was calculated. Secondly, large number of $2 \mathrm{D}$ and 3D body measurements were taken by 3D body scanning technology. Finally, body measurements were assessed in catch and finish posture, while the subject sat on the rowing ergometer. These were taken manually due to the large size of the ergometer and limited volume of the 3D Body scanner Symcad (Telmat) among others. All the measurements were completed on the same (competition) day, before or after completing a rowing race.

\subsection{Test suit}

All the subjects wore a similar test suit to prevent alterations of body measurements during both 3D body scanning and manual assessment (section 2.2.1). Typically a competition rowing suit is a full body, sleeveless garment with short pants above the knee, but during training, especially in the cold seasons, short or long-sleeved shirts are worn underneath. The test suit developed for the purpose of this study was a polyester-elastane short-sleeve unisuit in white color, provided by a zip in the front panel to facilitate dressing/downing and by a black line, digital-printed on the back panel (Figure 1). Five body measurements were selected namely upper-arm girth (UAG), thigh girth (TG), knee girth (KG), back length $(B L)$ and across back width (BW). All measurements were taken manually according to ISO 8559-1: 2017 except BL and BW. For practical reasons and to assist the operator in taking quick measurements, especially in dynamic positions, $\mathrm{BL}$ was measured along the black line (neckline-upper hip level). The absolute value of the measured BL is slightly higher than the real back length of the subject (ISO 8559-1, measured from $7^{\text {th }}$ cervical to waist). This is however acceptable for the purpose of this study, which quantifies relative variation of back length upon postures, given that the fabrics of the test suits have the same elasticity and because the tight design of the suit keeps the guidance line in place. For the same reasons, the across back width (BW) was measured taking the sleeve seams as guidance (Figure $1 \mathrm{~b}$ ). Most of heavyweight male rowers encountered fitting problems with the test suit labeled by the manufacturer from $S$ 
to XXL. Therefore best fitting garment was not selected based on garment size usually worn by the subject but instead based on his/her comfort sensation and visual assessment by the experienced operator.

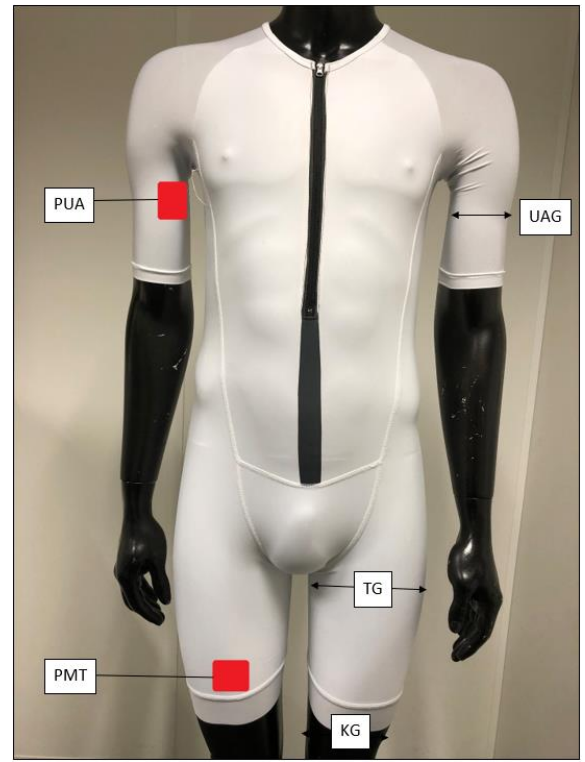

a)

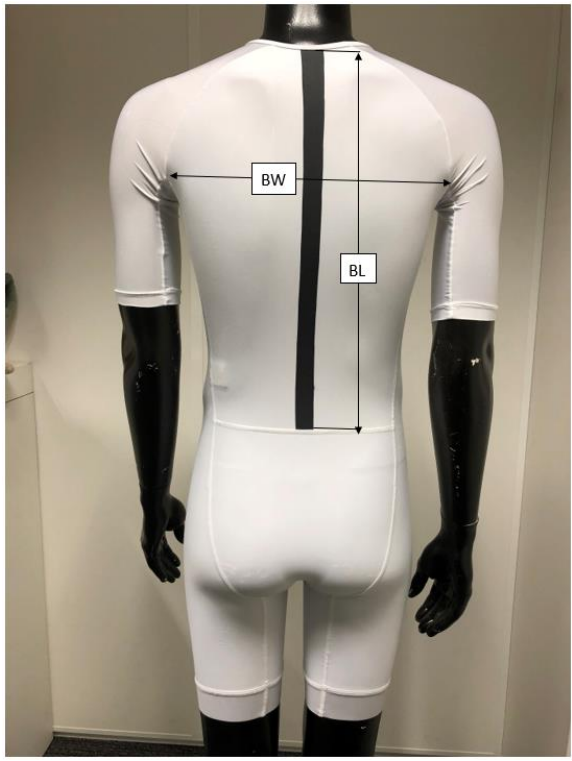

b)

Figure 1 Test suit a) front and b) back view, with indication of the different body measurement locations

\subsection{Body measurements and skin-test suit interface pressure assessment}

\subsubsection{Manual assessment of body changes with rowing posture}

During a rowing stroke, four positions can be distinguished among which flexed posture "catch" and extended posture "finish" potentially lead to significant body changes, both in lengths and girths. During the catch (Figure 2 a) the legs are compressed, the shins are vertical, arms are extended, triceps work to extend the arms, and the flexor muscles of the fingers and thumbs grip the handle. The back muscles are relaxed, and abdominals are flexing the torso forward. At the finish (Figure $2 \mathrm{c}$ ), the abdominals stabilize the body, and the glutes and quads are contracting. The biceps and many of the back muscles are also contracting to help keep the torso in the finish position and to internally rotate the upper-arms. 


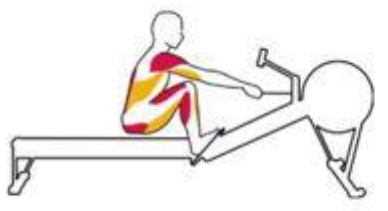

a)

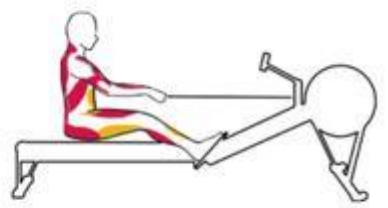

b)

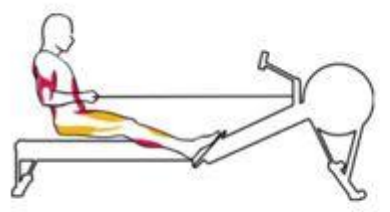

c)

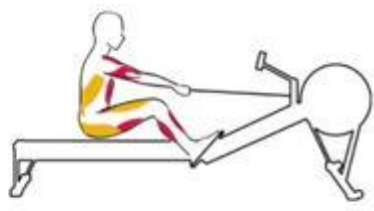

d)

Figure 2 Rowing stroke and muscle involved in a) catch, b) drive, c) finish, d) recovery (permission from Concept2, Inc.)

Changes of both upper and lower limbs upon posture are relevant for the purpose of garment development in general and they likely change most upon catch and finish posture. A tape measure was used to assess these body measurements for each subject in catch, finish and static (A-stand) position. For each subject, markers were placed on the his body to ensure consistency during the three postures. To reproduce the rowing movements with high fidelity, the subjects executed the two movements while sitting on an ergometer.

\subsubsection{Skin-test suit interface pressure assessment}

A PicoPress instrument (Microlab, 2019) was used to assess the interface pressure between the sportswear and the skin. PicoPress operates in the rage of 1-189 $\mathrm{mmHg}$ with steps of $1 \mathrm{mmHg}$. Picopress contains a manometer connected to a thin wall, flexible, circular plastic bladder with a diameter of $5 \mathrm{~cm}$. Before starting the measurement the probe is filled with $2 \mathrm{~mL}$ of air which expands the thickness of the probe to less than 3 mm (Partsch, 2010). Two body locations were selected namely upper-arm (PUA) and midthigh (PMT), as shown in Figure 1. These body locations were selected based on a compromise between assumed largest pressure variation with postures, limited accessibility of the probe sensor to other body zones due to both garment and PicoPress design as well as privacy reasons of the test person. A t-test was applied to assess statistical significant differences between the body measurements and pressure in static and each dynamic posture.

\section{Results and discussions}

\subsection{Demographics of the target group}


A total number of $\mathrm{N}=74$ male and female elite rowers from different countries and categories were measured and their average demographics are shown in Table 1. We report the values as mean $(M) \pm S D$, with $S D$ the standard deviation, as well as the median, minimum and maximum values. The elite male rowers of age $21.0 \pm 4.0$ years had an average height of $183.6 \pm 6.8 \mathrm{~cm}$, body mass of $80.5 \pm 9.2 \mathrm{~kg}$ and BMI $23.8 \pm 1.9 \mathrm{~kg} / \mathrm{m}^{2}$. Similarly the female subjects of age $20.8 \pm 7.0$ years were $170.2 \pm 4.4 \mathrm{~cm}$ tall, with a body mass of $64.7 \pm 7.6 \mathrm{~kg}$ and $\mathrm{BMI} 22.3 \pm 2.5 \mathrm{~kg} / \mathrm{m}^{2}$. Most of male and female rowers were Belgian (i.e., 32 male and 14 female respectively). More than half of the female subjects (13 of total 20 ) and most of the males (41 of total 54 ) belonged to the heavyweight category.

Table 1 Demographic characteristics of male and female rowers

\begin{tabular}{|l|c|c|c|c|c|c|c|c|}
\hline $\begin{array}{l}\text { Total subjects } \\
(\mathrm{LW} / \mathrm{HW})\end{array}$ & \multicolumn{4}{|c|}{ Male (M):54 $\left(13^{(1)} / 41^{(2)}\right)$} & \multicolumn{3}{c|}{ Female (F): $20\left(7^{(3)} / 13^{(4)}\right)$} \\
\hline & M \pm SD & median & min & max & M \pm SD & median & min & max \\
\hline Age $(\mathrm{y})$ & $21.0 \pm 4.0$ & 20 & 17 & 35 & $21 \pm 7.0$ & 19 & 15 & 44 \\
\hline Height $(\mathrm{cm})$ & $183.6 \pm 6.8$ & 184.1 & 171.4 & 205.0 & $170.2 \pm 4.4$ & 169.9 & 163.7 & 179.0 \\
\hline Body mass $(\mathrm{kg})$ & $80.5 \pm 9.2$ & 79.2 & 62.9 & 99.8 & $64.7 \pm 7.6$ & 63.3 & 54.0 & 84.5 \\
\hline BMI $\left(\mathrm{kg} / \mathrm{m}^{2}\right)$ & $23.8 \pm 1.9$ & 23.7 & 19.9 & 29.2 & $22.3 \pm 2.5$ & 22.0 & 19.3 & 29.5 \\
\hline
\end{tabular}

LW-lightweight; HW-heavyweight; (1) 6 subjects from Belgium, 5 Ireland, 1 Cyprus, 1 Algeria; (2) 26 Belgium, 6 UK, 4 Portugal, 2 Ireland, 1 Tunisia, 1 Algeria, 1 Cyprus; (3) 4 Belgium, 2 Algeria, 1Tunisia; (4) 10 Belgium, 2 Ireland, 1Tunisia.

\subsection{Male rowers: variation of selected anthropometrics and skin-sportswear interface pressure with rowing dynamic postures}

In Table 2 the mean body measurements and skin-sportswear interface pressure are listed for male rowers in static and two sport postures . For instance, catch posture negatively affected the upper-arm girth (UAG) and thigh girth (TG) and positively the knee girth (KG), back length (BL) and width (BW). On the contrary, the finish position led to a decrease of back length and an increase of upper-arm (UAG) and thigh girth (TG) as well as back length $(\mathrm{BL})$. The mean interface pressures on upper-arm (PUA) were low (bellow $5 \mathrm{mmHg}$ ) and the maximum pressure of $10 \mathrm{mmHg}$ was registered on the thigh in the catch 
posture. Generally, the standard deviation (SD) of body measurements was in relative terms lower than those of pressure, as shown in Table 2.

Table 2 Male rowers: mean anthropometrics and skin-sportswear interface pressure in static and two dynamic postures (catch and finish)

\begin{tabular}{|c|c|c|c|c|c|c|c|}
\hline Posture & $\begin{array}{l}\text { UAG } \\
(\mathrm{cm})\end{array}$ & $\begin{array}{l}\text { TG } \\
(\mathrm{cm})\end{array}$ & $\begin{array}{l}\mathrm{KG} \\
(\mathrm{cm})\end{array}$ & $\begin{array}{c}\mathrm{BL} \\
(\mathrm{cm})\end{array}$ & $\begin{array}{l}\text { BW } \\
(\mathrm{cm})\end{array}$ & $\begin{array}{c}\text { PUA } \\
(\mathrm{mmHg})\end{array}$ & $\begin{array}{c}\text { PMT } \\
(\mathrm{mmHg})\end{array}$ \\
\hline $\begin{array}{c}\text { Static } \\
\text { 只 }\end{array}$ & $30.2 \pm 1.9$ & $59.5 \pm 3.9$ & $44.6 \pm 4.4$ & $49.9 \pm 2.4$ & $39.6 \pm 2.6$ & $3 \pm 2$ & $7 \pm 2$ \\
\hline $\begin{array}{l}\text { Catch } \\
\frac{9}{1}\end{array}$ & $29.8 \pm 1.7$ & $58.5 \pm 3.7$ & $47.4 \pm 3.4$ & $56 \pm 2.9$ & $46.1 \pm 4.1$ & $4 \pm 3$ & $10 \pm 2$ \\
\hline $\begin{array}{l}\text { Finish } \\
\text { q }\end{array}$ & $33.5 \pm 2.3$ & $60.1 \pm 3.4$ & $44.1 \pm 4.3$ & $52.2 \pm 2.4$ & $36.2 \pm 3.5$ & $5 \pm 2$ & $7 \pm 2$ \\
\hline
\end{tabular}

UAG-Upper-arm girth; TG- Thigh girth; KG- Knee girth; BL- Back length; BW-across Back width; PUA-

Pressure upper-arm; PMT- Pressure mid-thigh

Statistical significant differences of body measurements and pressure between catch-static posture and finish-static posture are shown in Table 3. Especially the catch position seems to result in the largest changes of above $6 \mathrm{~cm}$ for the back length (BL) and across back width (BW) and knee girth (KG) of almost $3 \mathrm{~cm}$. Back length $(\mathrm{BL})$ and across back width $(B W)$ also underwent large changes $(+2.3 \mathrm{~cm}$, respectively $-3.5 \mathrm{~cm})$ in finish posture while the upper arm girth (UAG) increased by $3.3 \mathrm{~cm}$. Catch-static pressure on the upper-arm remained almost constant similarly to finish-static pressure on thigh. The pressure exerted by sportswear on the thigh (PMT) increased with $4 \mathrm{mmHg}$ during the catch position and the pressure on the upper-arm increased during finish by $+2 \mathrm{mmHg}$.

Table 3 Male rowers: variation of anthropometrics and pressure with dynamic postures

\begin{tabular}{|l|c|c|c|c|}
\hline \multirow{2}{*}{$\begin{array}{l}\text { Body measurements and interface } \\
\text { pressure }\end{array}$} & \multicolumn{2}{|c|}{ Catch-Static } & \multicolumn{2}{c|}{ Finish-Static } \\
\cline { 2 - 5 } & difference & $p$-value & difference & $p$-value \\
\hline Upper-arm girth UAG $(\mathrm{cm})$ & $-0.4^{*}$ & $\mathrm{p}<0.01$ & $3.3^{*}$ & $\mathrm{p}<0.01$ \\
\hline
\end{tabular}




\begin{tabular}{|l|c|c|c|c|}
\hline Thigh girth TG $(\mathrm{cm})$ & $-1^{*}$ & $\mathrm{p}<0.01$ & $0.6^{*}$ & $\mathrm{p}<0.01$ \\
\hline Knee girth KG $(\mathrm{cm})$ & $2.8^{*}$ & $\mathrm{p}<0.01$ & -0.5 & $\mathrm{p}=0.2$ \\
\hline Back length BL $(\mathrm{cm})$ & $6.1^{*}$ & $\mathrm{p}<0.01$ & $2.3^{*}$ & $\mathrm{p}<0.01$ \\
\hline Across back width BW $(\mathrm{cm})^{(1)}$ & $6.5^{\star}$ & $\mathrm{p}<0.01$ & $-3.5^{\star}$ & $\mathrm{p}<0.01$ \\
\hline Pressure upper-arm PUA $(\mathrm{mmHg})^{(2)}$ & 0 & $\mathrm{p}=0.15$ & $2^{*}$ & $\mathrm{p}<0.01$ \\
\hline Pressure mid-thigh PMT $(\mathrm{mmHg})^{(3)}$ & $4^{*}$ & $\mathrm{p}<0.01$ & 0 & $\mathrm{p}=0.3$ \\
\hline
\end{tabular}

${ }^{*}$ paired t-test, significant differences $(\mathrm{p}<0.01) ; \mathrm{N}=54$ subjects for girth upper-arms/thigh/knee and back length; (1) measured for $\mathrm{N}=22$ subjects; (2)measured for $\mathrm{N}=38$ subjects; (3) measured for $\mathrm{N}=37$ subjects.

Relative changes (\%) of body measurements and interface pressure upon posture are displayed in Figure $3 \mathrm{a}$ and $\mathrm{b}$ respectively.

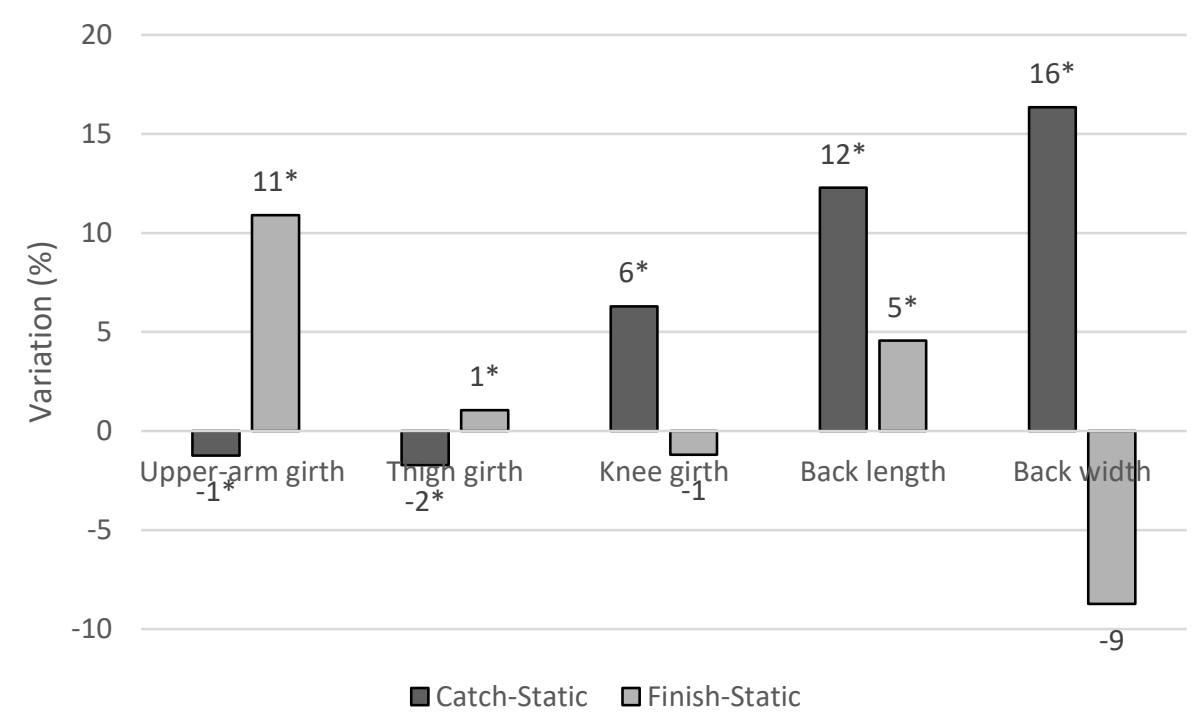

(a)

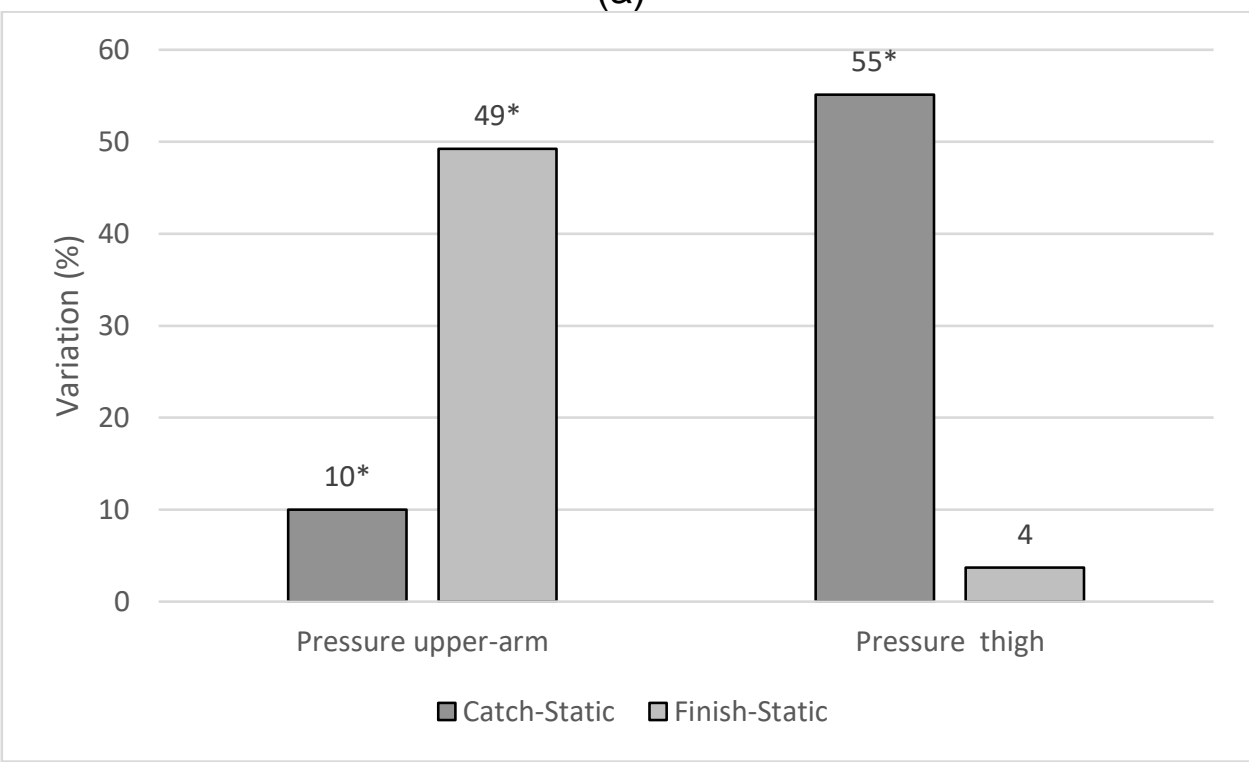

(b) 
Figure 3 Male rowers: relative variation (\%) static-dynamic posture of (a) selected anthropometrics and (b) pressure on upper-arm and thigh; " paired t-test, significant differences $(p<0.01)$

All the changes static-catch position were statistically significant $(p<0.01)$. Across back width (BW) had the largest increase (16\%) in catch position followed by back length $(12 \%)$ and knee girth (6\%). Thigh girth and upper-arm girth also significantly decrease with $2 \%$ in catch position as compared with static posture. All body measurements significantly changed upon finish posture except the knee girth. The largest increase was noticed for upper-arm girth (11\%) followed by back length $(5 \%)$. On the contrary, across back width significantly decreased in finish posture (9\%). Especially the interface pressure on thigh (PMT) and upper arm (PUA) drastically increased by $55 \%$ and $49 \%$ in finish posture and catch posture respectively, meaning an increase of $4 \mathrm{mmHg}$ and $2 \mathrm{mmHg}$ respectively, as shown in Table 3.

\subsection{Female rowers: variation of selected anthropometrics and skin- sportswear interface pressure with rowing dynamic postures}

The average anthropometrics of the female rowers and skin-sportswear interface pressure measured at five, respectively two, body locations are shown in Table 4. Catch posture negatively affected the thigh girth (TG) and positively the knee girth (KG), back length (BL), across back width (BW) and slightly the upper-arm girth (UAG). On the contrary, finish position led to a decrease of across back width (BW) and increase of other body measurements. Similarly to the male rowers, the mean interface pressure on upperarm (PUA) was low (bellow $4 \mathrm{mmHg}$ ) and the maximum pressure of $10 \mathrm{mmHg}$ was registered on the thigh, in the finish posture. Generally, variation (SD) of body measurements were in relative terms lower than those of interface pressure as shown in Table 4.

Table 4 Female rowers: mean anthropometrics and skin-sportswear interface pressure in static and two dynamic postures (catch and finish)

\begin{tabular}{|c|c|c|c|c|c|c|c|}
\hline Posture & $\begin{array}{c}\text { UAG } \\
(\mathrm{cm})\end{array}$ & $\begin{array}{c}\mathrm{TG} \\
(\mathrm{cm})\end{array}$ & $\begin{array}{c}\mathrm{KG} \\
(\mathrm{cm})\end{array}$ & $\begin{array}{c}\mathrm{BL} \\
(\mathrm{cm})\end{array}$ & $\begin{array}{c}\text { BW } \\
(\mathrm{cm})\end{array}$ & $\begin{array}{c}\text { PUA } \\
(\mathrm{mmHg})\end{array}$ & $\begin{array}{c}\text { PMT } \\
(\mathrm{mmHg})\end{array}$ \\
\hline $\begin{array}{c}\text { Static } \\
\text { 市 }\end{array}$ & $27 \pm 2.1$ & $\begin{array}{c}58.7 \\
\pm 5\end{array}$ & $41.9 \pm 3.7$ & $45.9 \pm 1.6$ & $34.7 \pm 2.2$ & $3 \pm 1$ & $6 \pm 1$ \\
\hline
\end{tabular}




\begin{tabular}{|c|c|c|c|c|c|c|c|}
\hline $\begin{array}{c}\text { Catch } \\
\frac{9}{\text { И }}\end{array}$ & $27.2 \pm 2.7$ & $57.3 \pm 5.4$ & $44.9 \pm 3.6$ & $50.8 \pm 3.4$ & $39.4 \pm 3.1$ & $3 \pm 1$ & $10 \pm 3$ \\
\hline $\begin{array}{c}\text { Finish } \\
\text { \& }\end{array}$ & $29.3 \pm 2.5$ & $59 \pm 4.6$ & $41.1 \pm 3.9$ & $47.6 \pm 2$ & $32.3 \pm 2.9$ & $4 \pm 2$ & $6 \pm 2$ \\
\hline
\end{tabular}

UAG-Upper-arm girth; TG- Thigh girth; KG- Knee girth; BL- Back length; BW-across back width; PUA-

Pressure upper-arm; PMT- Pressure mid-thigh

Significant differences of body measurements and pressure between static-catch posture and static-finish posture are shown in Table 5. Similarly to the male rowers, especially catch position resulted in the largest changes of around $5 \mathrm{~cm}$ for the back length $(\mathrm{BL})$ and across back width (BW) and knee girth $(K G)$ of almost $3 \mathrm{~cm}$. Back length (BL) and width $(B W)$ also largely changed $(+1.7 \mathrm{~cm}$, respectively $-2.5 \mathrm{~cm})$ in finish posture and the upper arm girth (UAG) increased by $2.3 \mathrm{~cm}$. Pressure on the upper-arm (PUA) and thigh (PMT) remained generally constant in catch and finish posture respectively. The pressure exerted by sportswear on the mid-thigh (PMT) increased with $5 \mathrm{mmHg}$ during the catch position similarly to the pressure on upper arm (PUA) during finish $(+1 \mathrm{mmHg})$.

Table 5 Female rowers: variation of anthropometrics and skin-sportswear interface pressure with dynamic postures

\begin{tabular}{|l|c|c|c|c|}
\hline \multirow{2}{*}{$\begin{array}{l}\text { Body measurements and interface } \\
\text { pressure }\end{array}$} & \multicolumn{2}{|c|}{ Catch-Static } & \multicolumn{2}{c|}{ Finish-Static } \\
\cline { 2 - 5 } & difference & $\mathrm{p}$-value & difference & $\mathrm{p}$-value \\
\hline Upper-arm girth UAG (cm) & 0.2 & $\mathrm{p}=0.5$ & $2.3^{*}$ & $\mathrm{p}<0.01$ \\
\hline Thigh girth TG(cm) & $-1^{*}$ & $\mathrm{p}=0.01$ & 0.3 & $\mathrm{p}=0.7$ \\
\hline Knee girth KG $(\mathrm{cm})$ & 2.9 & $\mathrm{p}=0.02$ & -0.8 & $\mathrm{p}=0.5$ \\
\hline Across back length BL (cm) & $4.9^{*}$ & $\mathrm{p}<0.01$ & $1.7^{*}$ & $\mathrm{p}<0.01$ \\
\hline Back width BW $(\mathrm{cm})^{(1)}$ & $4.7^{*}$ & $\mathrm{p}<0.01$ & -2.5 & $\mathrm{p}=0.1$ \\
\hline Pressure upper-arm PUA $(\mathrm{mmHg})^{(2)}$ & 0 & $\mathrm{p}=0.6$ & $1^{*}$ & $\mathrm{p}<0.01$ \\
\hline Pressure mid-thigh PMT $(\mathrm{mmHg})^{(3)}$ & $5^{*}$ & $\mathrm{p}<0.01$ & 1 & $\mathrm{p}=0.17$ \\
\hline
\end{tabular}

*paired t-test, significant differences ( $p<0.01) ; \mathrm{N}=20$ for girth upper-arm/thigh/knee and back length; (1) measured for $\mathrm{N}=6$ subjects; (2) measured for $\mathrm{N}=13$ subjects; ${ }^{(3)}$ measured on $\mathrm{N}=14$ subjects

Relative changes (\%) of body measurements and interface pressure upon posture are displayed in Figure $4 \mathrm{a}$ and $\mathrm{b}$ respectively. Almost all static-catch body changes were statistically significant $(p<0.01)$. Across back width $(B W)$ had the largest increase $(13 \%)$ in 
catch position followed by back length (11\%) and knee girth (7\%) and the values for male and females were comparable. Thigh girth (TG) significantly decreased in catch position as compared with static posture by $2 \%$. All body measurements significantly changed upon finish posture except the knee and thigh girth. The largest increase was noticed for upper-arm girth $(+8 \%)$ followed by back length $(4 \%)$. On the contrary, the across back width (BW) decreased in finish posture (7\%) but the difference was not statistically significant. The relative changes of body measurements were comparable for male and female rowers. Especially the interface pressure on the thigh drastically increased by around $80 \%$ in finish posture, meaning an increase of $5 \mathrm{mmHg}$, as shown in Table 6 and the relative increase was larger than in the case of male rowers (i.e., 55\%).

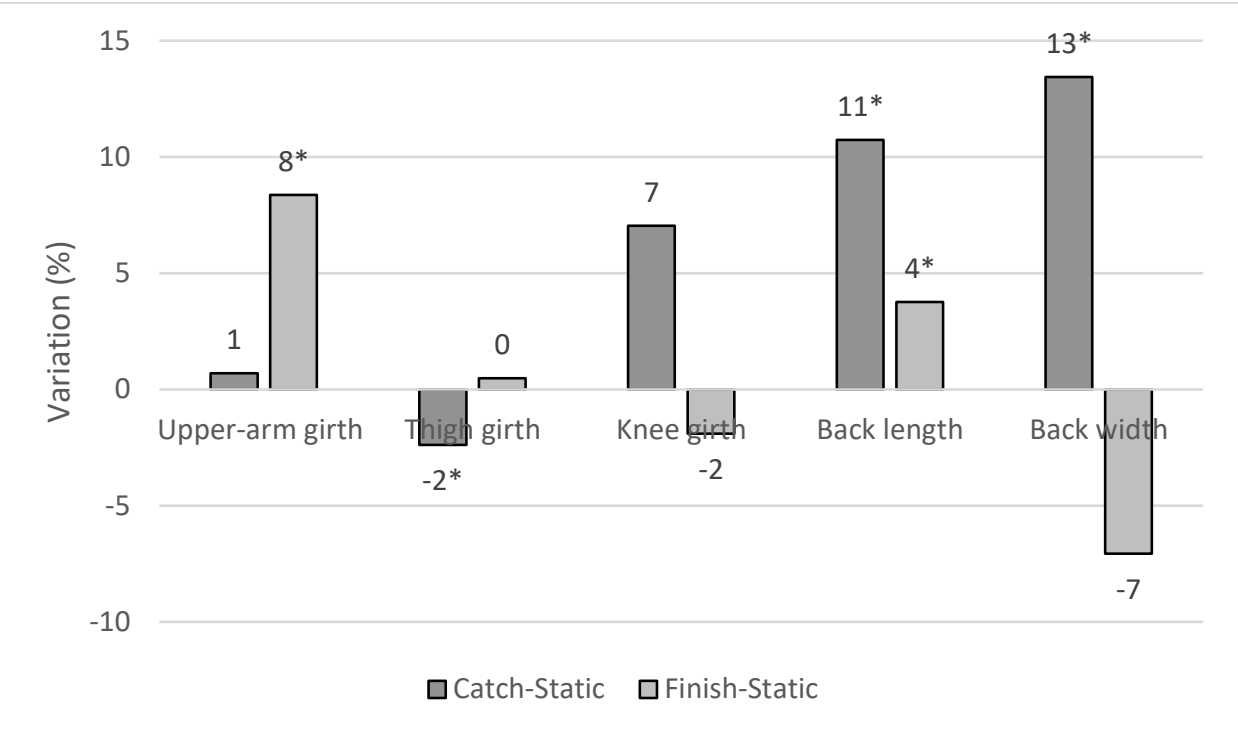

(a)

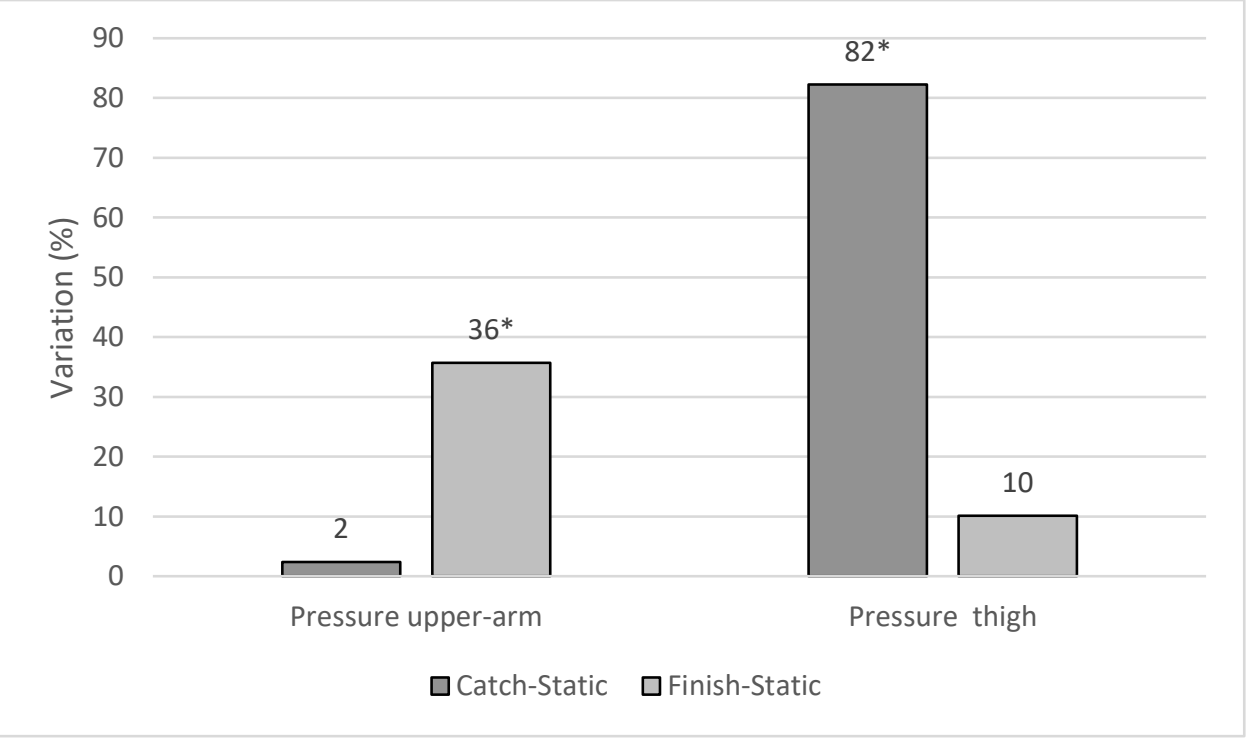

(b) 
Figure 4 Female rowers: relative variation (\%) static-dynamic posture of (a) selected anthropometrics and (b) pressure on upper-arm and thigh; " paired t-test, significant differences $(p<0.01)$

\subsection{Discussions}

Back length and width were most affected by rowing posture, which both increased especially in catch position for male subjects by $12 \%(6.1 \mathrm{~cm})$ and $16 \%(6.5 \mathrm{~cm})$ and by $11 \%(4.9 \mathrm{~cm})$ and $13 \%(4.7 \mathrm{~cm})$ respectively for female subjects. As the back length was not measured according to ISO 8559 but on the black guiding line, our absolute values must be higher than the real $\mathrm{BL}$, but the relative body measurement changes with the rowing posture are comparable with other studies depending on the posture investigated. Even relatively small posture changes seem to result in considerable body measurements changes for the purpose of garment development. For instance, previous research (Ernst and Detering-Koll 2014) reported body measurement changes of up to +4 $\mathrm{cm}$ only due to posture adopted during 3D body scanning. Furthermore it seems that back width of a trained subject may increase up to $6.5 \mathrm{~cm}$ and arm length by $5 \mathrm{~cm}$ when the muscles are strained during exercise (De Raeve and Vasile 2016). (Choi and Ashdown 2010) evaluated the differences in body measurements between standing and siting postures and reported an increase of waist girth by $8 \%$, hip girth by $7 \%$, mid-thigh girth by $9.6 \%$ and the knee girth by $17 \%$ in the sitting posture. Body measurement changes seem to be larger from standing to sitting posture as compared with changes from standing to rowing posture. For instance, the knee girth of male rowers increased only by $2.8 \mathrm{~cm}(6 \%)$ in catch position and by $2.9 \mathrm{~cm}(7 \%)$ for female subjects respectively. As the short pants of the test suit don't reach the knee, the knee girth was not measured according to ISO 8559 but above the knee, on the same place for all subjects, therefore only relative increase should be compared with other studies. Posture change from stand to catch and finish only moderately affected the thigh girth of male and female subjects of maximum 1 $\mathrm{cm}$ increase in finish posture. Other studies (Loercher et al. 2017) also reported larger variation of back length as opposed to our case of $12.3 \mathrm{~cm}(21.5 \%)$. These were however valid for a man with reported garment size 50 during position switch from standing to forward bent position, which is typically larger than the static-dynamic posture changes we considered.

As illustrated in Figure $1 \mathrm{a}$, during the catch posture the legs are compressed and the arms are extended which can explain the increase of knee girth (6\%) and the skin- 
sportswear interface pressure on thigh (16\%) and slight decrease of upper-arm girth (-1\%). Moreover the back muscles are relaxed and abdominals are flexing the torso forward which may explain the average increase of male back length (12\%) and across back width (16\%). At the finish posture (Figure $1 \mathrm{c}$ ), the abdominals stabilize the body, and the glutes and quads are contracting. The thigh girth is slightly decreasing (2\%), but the mid-thigh pressure is strongly increasing (55\%), which is explained by the different girth and pressure measurement locations as shown in Figure 2. The biceps and many of the back muscles are also contracting to help keep the torso in the finish position and to internally rotate the upper arms. That can explain the increase of upper-arm girth (11\%) and high increase of pressure on upper-arm (49\%) while average thigh girth and back length of male has a smaller increase (1\%, respectively 5\%). (Engel and Sperlich 2016) summarized the results of around 55 studies dealing with effect of compression sportswear on performance and recovery in endurance athletes. Typical skin-sportswear interface pressure ranged between 6-45 $\mathrm{mmHg}$, mostly $10-20 \mathrm{mmHg}$ for tights and above around 20-30 up to $40 \mathrm{mmHg}$ for compression socks. The skin-sportswear interface pressure found in this study increased largely with the posture but the absolute values registered were below $10 \mathrm{mmHg}$ which remains a relatively low pressure and thus provides adequate garment pressure comfort during sport.

\subsection{Garment fit in rowing postures}

\subsubsection{Prototypes development}

Existing competition rowing suits were analyzed and the final design and fabrics were selected taking into consideration the feedback from the rowers. Three types of fabrics typically used for sportswear exhibiting various composition, elasticity and moisture management properties were selected for the development of the prototypes, see Table 6 where mean values are given and SD again indicated via \pm .

Table 6 Physical and comfort-related properties of fabrics used

\begin{tabular}{|l|c|c|c|c|}
\hline & Fabric 1 & Fabric 2 & Fabric 3 & Fabric 4 \\
\hline Composition (\%) & $81 \mathrm{PES} /$ & $76 \mathrm{PA} / 13 \mathrm{PES} /$ & $71 \mathrm{PA} /$ & $75 \mathrm{PES} / 25 \mathrm{EA}$ \\
& $19 \mathrm{EA}$ & $11 \mathrm{EA}$ & $29 \mathrm{EA}$ & \\
\hline Mass $\left(\mathrm{g} / \mathrm{m}^{2}\right)^{(1)}$ & $156 \pm 2$ & $156 \pm 4$ & $147 \pm 5$ & $257 \pm 10$ \\
\hline
\end{tabular}




\begin{tabular}{|l|l|c|c|c|c|}
\hline \multicolumn{2}{|l|}{ Thickness (mm) (2) } & $0.5 \pm 0.00$ & $0.6 \pm 0.01$ & $0.42 \pm 0.00$ & $0.66 \pm 0.04$ \\
\hline \multirow{2}{*}{ Elongation (\%) ${ }^{(3)}$} & wales/warp & $155 \pm 2$ & $128 \pm 4$ & $89 \pm 1$ & $119 \pm 12$ \\
\cline { 2 - 6 } & course/weft & $223 \pm 3$ & $99 \pm 2$ & $95 \pm 1$ & $114 \pm 1.5$ \\
\hline \multicolumn{2}{|l|}{ Air permeability (mm/s) ${ }^{(4)}$} & $258 \pm 3$ & $1394 \pm 45$ & $105 \pm 11$ & - \\
\hline OMMC (5) & $04 \pm 0.04$ & $0.56 \pm 0.02$ & 0 & - \\
\hline Drying time (min) & $(6)$ & $46 \pm 0.4$ & $28 \pm 0.3$ & - & - \\
\hline
\end{tabular}

PES-polyester; PA-polyamide; EA-elastane; (1)ISO 3801:1997; (2)ISO 5084:1996; (3) EN

14704-1:2005; (4) ISO 9237: 1995; ${ }^{(5)}$ AATCC-195: 2001; (6) ISO 17617:2014

Knitted fabric 1 was used on the front panel, knitted fabric 2 with elevated air permeability, moisture management and shorter drying time on the back side and low elasticity, waterproof woven fabric 3 on the buttocks respectively. Double-folded fabric 1 was used for the lower part of the pants. Sizing charts for male rowers (De Raeve et al, 2018) were used for development of the prototypes. They were constructed based on average body measurements of a dataset of $\mathrm{N}=52$ elite male rowers taken by 3D Body scanning in an A-posture. Chest girth was defined as primary dimension according to ISO 8559-2:2017. The subjects were categorized in 8 different size groups (44-58) according to the recommended size ranges (EN 13402-3: 2017). A sleeveless prototype called MR58 was developed for a male rower garment size 58. A second prototype MR58-CP was created by augmenting the back length BL of prototype MR58 by $12 \%$, back width BW by $16 \%$ and knee girth KG by $6 \%$ according to maximum body changes upon catch posture.

\subsubsection{Garment fit assessment}

Fit of the prototypes MR58 and MR58-CP was virtually assessed by 3D Fit software (Lectra) on an avatar corresponding to a rower size 58 (in static posture). Fabrics from the library of the software (having similar properties to fabrics 1-3) were used for fit simulation. An adequate fit of the prototype MR58 can be observed in Figure 5a while Figure $5 \mathrm{~b}$ shows a poor fit of the prototype MR58-CP. 


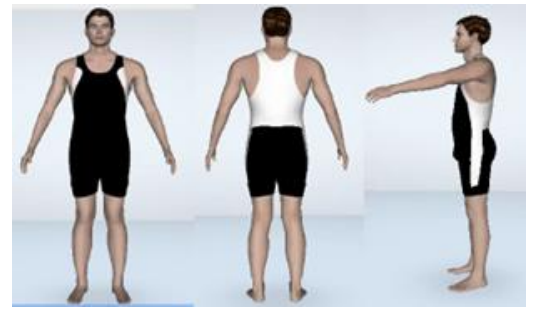

(a)

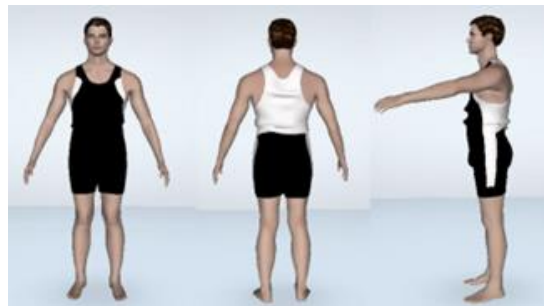

(b)

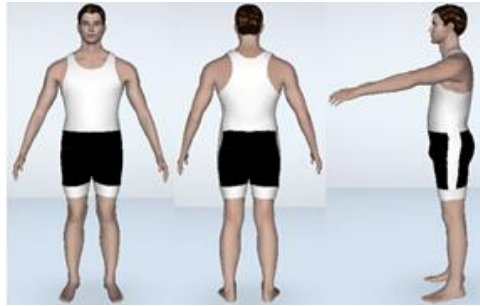

(c)

Figure 5 Virtual fit assessment of prototype MR58 (a), MR58-CP (b) and MR58-FP (c) on an avatar rower size 58: front, back and side view

The two prototypes were also subjectively assessed both in static and dynamic postures by an elite male rower, age 23 , with body measurement corresponding to size 58 , having previous garment fitting questionnaire experience. Overall fit and other fit features were evaluated in static and dynamic postures and the scores are given in Table 7, where score 1 indicates a bad fit and score 5 an excellent fit.

Table 7 Overall and local fit assessment of prototypes MR58, MR58-CP and MR58-FP in static $(S)$, catch $(C)$ and finish $(F)$ posture, where 1- bad fit and 5- excellent fit

\begin{tabular}{|l|c|c|c|c|c|c|c|c|c|}
\hline \multirow{2}{*}{} & \multicolumn{3}{|c|}{ MR58 } & \multicolumn{3}{c|}{ MR58-CP } & \multicolumn{3}{c|}{ MR58-FP } \\
\cline { 2 - 11 } & S & C & F & S & C & F & S & C & F \\
\hline Overall fit & 4 & 4 & 4 & 3 & 3 & 3 & 4.5 & 4.5 & 4.5 \\
\hline CG & 4 & 4 & 4 & 2.5 & 4 & 3 & 4 & 4.5 & 4.5 \\
\hline WG front & 4 & 4 & 4 & 2.5 & 3 & 2.5 & 4 & 4.5 & 4.5 \\
\hline WG back & 5 & 4 & 4 & 2.5 & 4 & 4 & 4 & 4.5 & 4.5 \\
\hline HG & 4 & 3 & 3 & 3.5 & 2.5 & 2.5 & 4 & 4 & 4 \\
\hline TG & 4 & 4 & 4 & 3 & 2.5 & 2.5 & 4 & 4.5 & 4.5 \\
\hline BL & 4 & 5 & 5 & 2 & 3 & 3 & 3.5 & 5 & 5 \\
\hline LL & 2 & 3 & 3 & 3 & 3 & 3 & 5 & 5 & 5 \\
\hline neck line front & 4 & 4 & 4 & 4 & 4 & 4 & 5 & 5 & 5 \\
\hline armhole front & 4 & 3 & 3 & 3 & 2 & 2 & 4 & 3 & 4 \\
\hline armhole cut back & 4 & 5 & 5 & 3 & 3 & 3 & 5 & 5 & 5 \\
\hline
\end{tabular}

CG- chest girth, WG-waist girth, HG- hip girth, TG- tigh girth, BL- back length, LL- leg (pants) length 
The scores assigned by the test person indicate that prototype MR58 has generally a very good fit (score 4 or above) in static and dynamic postures, a good fit on hip girth HG (score 3 ) and less good length of the pants LL (score 2-3). The subject preferred tighter and shorter pants which should not roll up during movement. Due to the amendments done to the back panel encompassing increases of back width and length, prototype MR58-CP felt large both at level of chest and waist (low scores of 2.5) in static posture $S$ but scored better in dynamic postures $\mathrm{C}$ ( score 4 and 3 ) and $\mathrm{F}$ (score 3 and 2.5) respectively. The reason for this was that only the variation of back length $(B L)$ and width $(B W)$ due to the rowing postures were assessed and the patterns were modified accordingly. Front length and chest girth proved impracticable to measure accurately in catch and finish posture while respecting the privacy of the subject. Hence, the front patterns were not altered (shortened) which lead to a loose prototype at the chest and waist levels (i.e. upper garment length accommodated around the body waist) as the front width shortened in these positions.

A third prototype MR58-FP was made based on the experience obtained and input of the test person. For this prototype (Figure 6, green color) the length of back panel BL of MR58 was increased according to the finish posture (i.e. 5\%). Across back width (BW) and knee girth (KG) were kept similar to MR58-CP. Based on input of the test person, the front panel (1) was executed in two parts (1.1) and (1.2) with a seam foreseen at the level of the waist and fabric 2 replaced fabric 1 in the front panel, to provide more support and comfort Double folded strap (4) used at the lower part of the pants MR58 and MR58-CP was replaced by a $5 \mathrm{~cm}$ - width strip (fabric 4 , Table 6 ) which provides more grip and keeps the pants in place during rowing. Figure 6 shows all amendments applied to prototype MR58CP (blue color) and MR58-FP (green color). Cover stitch 605 (ISO 4915:1991) was used for assembling the patterns aiming at low stich-body friction. 


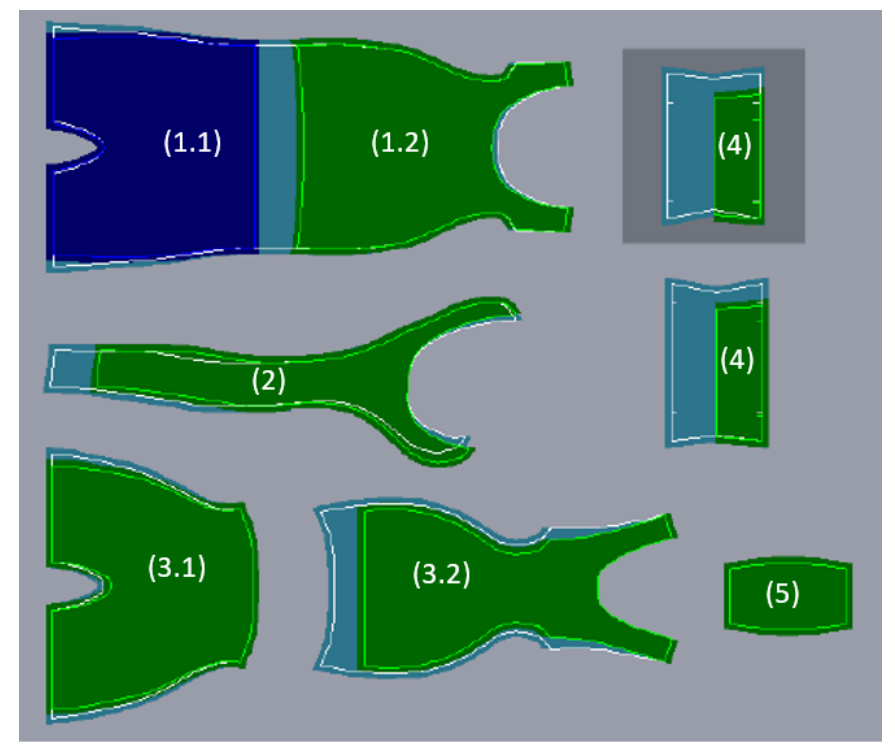

Figure 6 Patterns comparison of prototype MR58-CP (blue color) and MR58-FP (green color): front panels (1.1 and 1.2), side panels (2), back panels (3.1 and 3.2), pants straps (4) and crotch strap (5)

Virtual fit of the prototype MR58-FP can be seen in Figure 5c. The prototype was assessed few weeks later by the same experienced test person and the scores given are shown in Table 7. Prototype MR58-FP was found best of all, with most of the scores 4.5 or higher. The back length BL was still slightly long in static posture (score 3.5) but excellent (score 5) during rowing postures. A slightly deeper armhole was suggested for more comfort during the catch posture.

\section{Conclusions}

This study quantified the effect of two sport postures on several body measurements for a large group of competitive male and female rowers. Significant variations were found both for body measurements and skin-sportswear interface pressure depending on dynamic posture and regardless the gender. Prototype MR58 developed based on average elite male rowers body dimensions showed an adequate virtual fit and was positively evaluated by the experienced test person. For the considered fabrics and design, an increase of the garment pattern (i.e. back length, back width) by maximum changes found due to catch posture led to a poor fit of the prototype MR58-CP which was generally too large, especially in static posture. On the contrary, prototype MR58-FP, that considered some 
finish posture-related pattern changes instead, as well as design adjustments based on the experience of the first prototypes and input of the test person, had the best fit.

No size charts could be developed for the limited database of 20 females rowers to validate the garment fit in various postures. Fit evaluation was limited to a male test person and one garment size. Depending on elasticity of the fabric used, sportswear may accommodate some body changes due to posture therefore pattern amendments should be carefully considered. Preferably front length, chest and waist girth shall be also documented in rowing postures and considered during garment patterns alteration aiming at a better fit.

This study confirms however that collection of body measurements of the target group is essential for a good fit that can be further improved by considering both specific postures and requirements of the end user.

\section{Acknowledgments}

The test suits were produced by company Decca based on requirements of the authors. The authors acknowledge the support of the Flemish rowing federation, Sport Vlaanderen and rowing clubs for recruitment of test persons, company Bioracer for providing the fabrics and suggestions for design of the prototypes as well as Celien De Bisschop for developing the prototypes and assisting with subjective evaluation.

\section{Funding statement}

The authors acknowledge the financial support of VLAIO and co-financing of industrial partners in research project SHAPE Adapted Performance Wear (IWT TETRA HBC.2016.0078).

\section{References}

Bourgois, J., A. L. Claessens, J. Vrijens, R. Philippaerts, B. Van Renterghem, M. Thomis, M. Janssens, R. Loos \& J. Lefevre (2000) Anthropometric characteristics of elite male junior rowers. British Journal of Sports Medicine, 34, 213-216.

Bourgois, J., A. L. Claessens, M. Janssens, B. Van Renterghem, R. Loos, M. Thomis, R. Philippaerts, J. Lefevre \& J. Vrijens (2001) Anthropometric characteristics of elite female junior rowers. Journal of Sports Sciences, 19, 195-202. 
Braganca, S., M. Carvalho, P. Arezes \& S. P. Ashdown (2017) Work-wear pattern design to accommodate different working postures. International Journal of Clothing Science and Technology, 29, 294-313.

Bragança, S., P. Arezes, M. Carvalho \& S. Ashdown. (2016). Effects of Different Body Postures on Anthropometric Measures. In AHFE International Conference on Ergonomics in Design, ed. M. S. Francisco Rebelo, 313-322. Florida, USA: Springer.

Brophy-Williams, N., M. W. Driller, S. L. Halson, J. W. Fell \& C. M. Shing (2014) Evaluating the Kikuhime pressure monitor for use with sport compression clothing. Sport Engineering, 17, 55-60.

Chi, L. \& R. Kennon (2006) Body scanning of dynamic posture. International Journal of Clothing Science and Technology, 18, 166-178.

Choi, J. \& K. Hong (2015) 3D skin length deformation of lower body during knee joint flexion for the practical application of functional sportswear. Applied Ergonomics, 48, 186-201.

Choi, S. \& S. P. Ashdown (2010) Application of lower body girth change analysis using 3D Body scanning to pants patterns. Journal of Korean Society of Clothing and Textiles, 34 (6), 955-968.

Choi, S.\& S.P. Ashdown (2011) 3D body scan analysis of dimensional change in lower body measurements for active body positions. Textile Research Journal, 81, 81-93.

Claessens, A., J. Bourjois, K. Van Aken, R. Van der Auwera, R. Philippaerts, M. Thomis, J. Vrijens, R. Loos \& J. Lefevre (2005) Body proportions of elite male junior rowers in relation to competition level, rowing style and boat type. Kinesiology, 37 (2), 123132.

Coca, A., W. J. Williams, R. J. Roberge \& J. B. Powell (2010) Effects of fire fighter protective ensembles on mobility and performance. Applied Ergonomics, 41, 636641.

Concept2. https://www.concept2.com/indoor-rowers/training/muscles-used. Concept.2,

Training, muscles used., Accessed on 10 April 2019

De Raeve, A. \& S. Vasile (2016). Adapted performance wear. In 7th International Conference and Exhibition on 3D Body Scanning. Lugano, Switzerland.

De Raeve, A., S. Vasile, J. Cools, B. Malengier \& F. Deruyck (2018), SHAPE Adapted

Performance Sportswear (IWT TETRA HBC.2016.0078), final report 
Engel, F. \& B. Sperlich. 2016. Compression Garments in Sports: Athletic Performance and Recovery. Switzerland: Springer International Publishing.

Ernst, M. \& U. Detering-Koll. 2014. Posture dependency of 3D-Body scanning data for virtual product development process in apparel industry. In $5 t^{\text {th }}$ International conference on 3D Body Scanning Technologies. Lugano, Switzerland.

Forjasz, J. (2011) Anthropometric Typology of Male and Female Rowers Using K-Means Clustering. Journal of Human Kinetics, 28, 155-164.

Griffiths, L. A. \& A. K. McConnell (2012) The influence of rowing-related postures upon respiratory muscle pressure and flow generating capacity. European Journal of Applied Physiology, 112, 4143-4150.

Loercher, C., Morlock, S. \& Schenk, A. 2017. Motion-oriented 3D analysis of body measurements. In 17th World textile Conference AUTEX 2017. Corfu, Greece: IOP Conf. Seies: Materials Science and Engineering.

Loercher, C., Morlock, S. \& Schenk, A (2018) Design of a Motion-Oriented Size System for Optimizing Professional Clothing and Personal Protective Equipment. Journal of Fashion Technology\& Textile Enginering, S4:014.

Maqsood, M., Y. Nawab, J. Umar, M. Umair \& K. Shaker (2017) Comparison of compression properties of stretchable knitted fabrics and bi-stretch woven fabrics for compression garments. Journal of the Textile Institute, 108, 522-527.

Mikulic, P. (2008) Anthropometric and physiological profiles of rowers of varying ages and ranks. Kinesiology, 40, 80-88.

Mikulic,P., 2009, Anthropometric and metabolic determinants of 6,000-m rowing ergometer performance in internationally competitive rowers, Journal of strength and conditioning research, 23, 1851-1857.

Partsch, H. \& G. Mosti (2010) Comparison of three portable instruments to measure compression pressure. International Angiology, 29, 426-430.

Penichet-Tomas, A., Pueo, B.\& Jimenez-Olmedo, J.M., 2016, Realthionship between experience and training chracteristis with performace in non-Olympic rowing modalities, Journal of Physical Education and Sport, 16, 1273-127.7

Perera, A.D.P, Ariyasinghe, A.S. \& Makuloluwa, PTR (2015), Relathionship of competitive Succes to the physisque of Sri Lankan rowers, Ameroca, Journl of Sport Science and Medicine, 3, 61-65. 
Schranz, N., Tomkinson, G., Olds T. \& Daniell, N. (2010) Three-dimensional anthropometric analysis: Differences between elite Australian rowers and the general population. Journal of Sports Sciences, 28, 459-469.

Schranz, N., Tomkinson, G., Olds T., Petkov, J.\& Hahn, A.G. (2012), Is thereedimensional anthropometric analysis as good as traditional anthropometric analysis in predicting junior rowing performance?, Journal of Sport Sciences, 30, 1241-1248.

Sulaiman N., Hasim, N.M;, Adnan, R. \& Ismail, S.I. (2015), Relationship between selected anthropometrics and rowing performance among Malaysian elite rowers, proceedings of the $2^{\text {nd }}$ International Colloquium on Sport Science, Exercise, Engineering and Technology

Van den Kerckhove, E., S. Fieuws, P. Massage, R. Hierner, W. Boeckx, J. P. Deleuze, J. Laperre \& M. Anthonissen (2007) Reproducibility of repeated measurements with the Kikuhime pressure sensor under pressure garments in burn scar treatment. Burns, 33, 572-578.

Yoshiga, C., Kawakami, Y., Fukunaga, T., Okamura, K. and Higuchi, M., (2010) Anthropometric and Physiological Factors Predicting $2000 \mathrm{~m}$ Rowing Ergometer Performance Time, Adv. Exerc. Sports Physiol., 6, 51-57.

Wang, Y. J., P. Y. Mok, Y. Li \& Y. L. Kwok (2011) Body measurements of Chinese males in dynamic postures and application. Applied Ergonomics, 42, 900-912. 